\title{
Resolution of Posterior Fossa Extradural Haematoma by Conservative Treatment: A Case Report
}

\author{
Krishan Kumar Sharma ${ }^{1^{*}}$ and Asgar Ali \\ ${ }^{1}$ Department of Neurosurgery (Trauma \& Emergency), All India Institute of Medical Sciences Patna, Bihar, India \\ ${ }^{2}$ Department of Biochemistry, All India Institute of Medical Sciences Patna, Bihar, India
}

*Corresponding author: Dr. Krishan Kumar Sharma, Associate Professor, Department of Neurosurgery (Trauma \& Emergency), All India Institute of Medical Sciences, Phulwarisharif, Patna-801507, Bihar, India, E-mail: kksharma_5@yahoo.com

\begin{abstract}
Surgical intervention in posterior fossa extradural haematoma (PFEDH) carries very good results. But there are no defined indications for surgical evacuation when patient is asymptomatic and normal neurologically, even in the guidelines for surgical management of traumatic brain injury by 'the brain trauma foundation \& the congress of neurological surgeons'. Haematoma volume $>10$ $\mathrm{ml}$, haematoma thickness $>15 \mathrm{~mm}$, perimesencephalic cisterns obliteration, fourth ventricle displacement and hydrocephalus, are the criteria considered for surgical evacuation by most of neurosurgeons. Patient presented here was clinically asymptomatic with left PFEDH (volume $20 \mathrm{cc}$ and thickness $20 \mathrm{~mm}$ ) which should have undergone immediate surgical removal, treated conservatively showed complete resolution in six weeks' time. Conservative treatment seems to be a justified approach in asymptomatic PFEDH. However, a larger study is needed to to further support these findings.
\end{abstract}

\section{Keywords}

Posterior fossa extradural haematoma, Glasgow coma scale, CT scan head

\section{Introduction}

Posterior fossa extradural haematoma (PFEDH) often requires urgent surgical removal because of availability of limited space as compared to supratentorial compartment. According to the guidelines for surgical management of traumatic brain injury by 'the brain trauma foundation \& the congress of neurological surgeons [1], extra dural haematoma with volume greater than $30 \mathrm{ml}$ should undergo surgical evacuation, regardless of Glasgow coma scale [2]. PFEDH is not described separately in these guidelines. There are no definite guidelines when to operate and when not to operate a PFEDH in neurologically normal patients. According to some authors different criteria for surgical evacuation of PFEDH included are haematoma volume $>10 \mathrm{ml}$ [3], haematoma thickness $>15 \mathrm{~mm}$, perimesencephalic cisterns obliteration, fourth ventricle displacement and hydrocephalus [4]. Patient presented here was left PFEDH (volume $20 \mathrm{cc}$ ) and should have undergone immediate surgical removal. However, the patient was treated conservatively and showed complete resolution in six weeks time.

\section{Case Description}

A six-year-old boy sustained trauma due to fall from stairs (about seven feet height) and came to the hospital five days later. After trauma there was transient loss of consciousness for half an hour with repeated vomiting, which regressed completely in two days. On examination, pulse was 90 per minute, Glasgow Coma Scale was 15/15. Neurological examination was normal. CT scan head (Figure 1) showed left posterior fossa extradural haematoma ( $50 \times 20 \times 40 \mathrm{~mm}$, volume $20 \mathrm{cc}$ ). Patient was treated conservatively, kept under regular clinical and radiological observation. Neurologically, patient remained normal throughout. Left PFEDH haematoma showed marked resolution in CT scan head done after three weeks (Figure 2) and resolved completely in CT scan head done after six weeks (Figure 3).

\section{Discussion}

Traumatic PFEDH is very rare, approximately $0.3 \%$

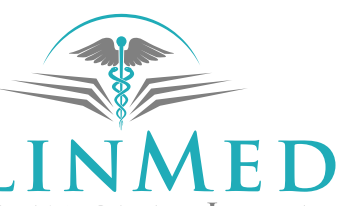

NTERNATIONAL LIBRARY

Citation: Sharma KK, Ali A (2021) Resolution of Posterior Fossa Extradural Haematoma by Conservative Treatment: A Case Report. Neurosurg Cases Rev 4:074. doi.org/10.23937/2643-4474/1710074 Accepted: July 26, 2021; Published: July 28, 2021

Copyright: (c) 2021 Sharma KK, et al. This is an open-access article distributed under the terms of the Creative Commons Attribution License, which permits unrestricted use, distribution, and reproduction in any medium, provided the original author and source are credited. 


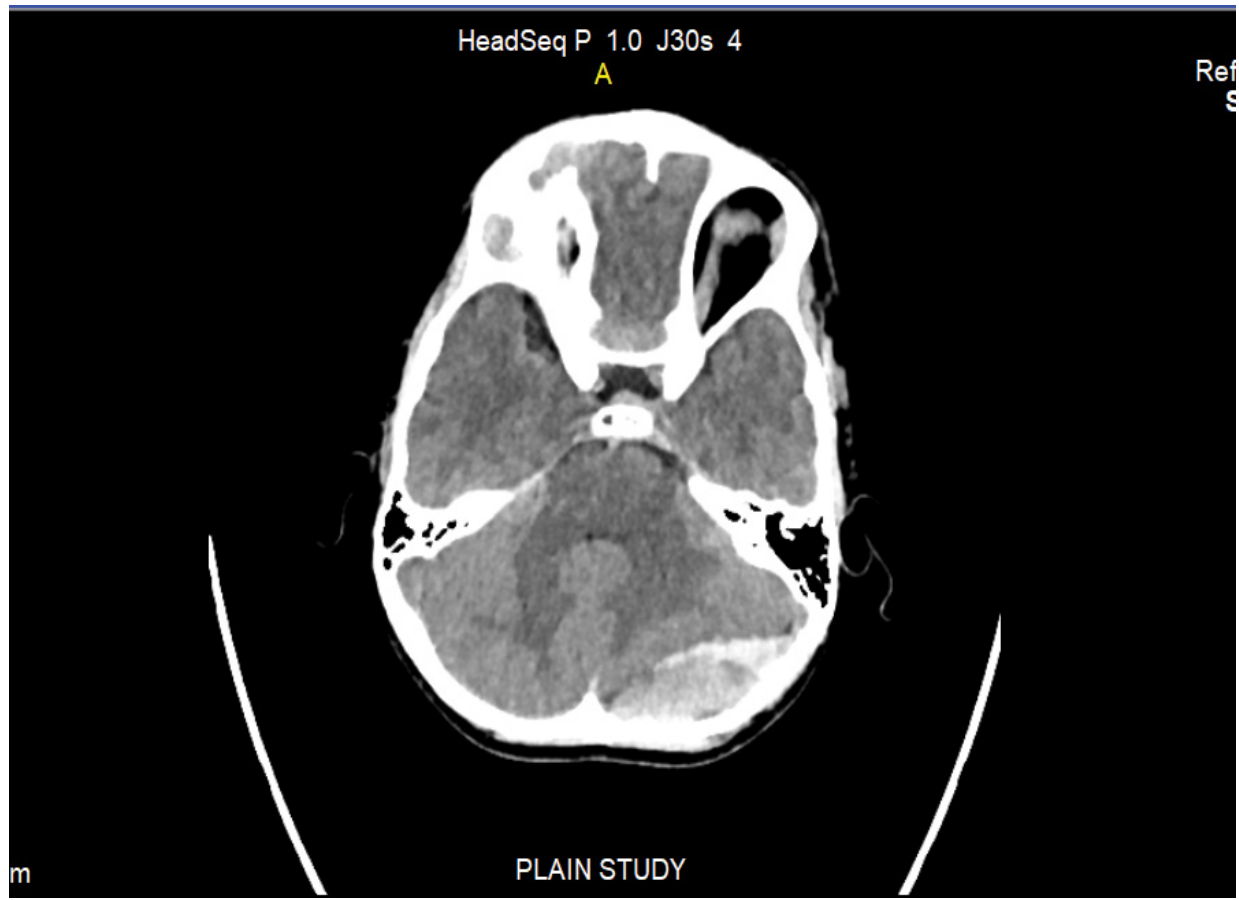

Figure 1: CT scan head ( $5^{\text {th }}$ post injury day) showed left posterior fossa extradural haematoma $(50 \times 20 \times 40 \mathrm{~mm}$, volume $20 \mathrm{cc})$.

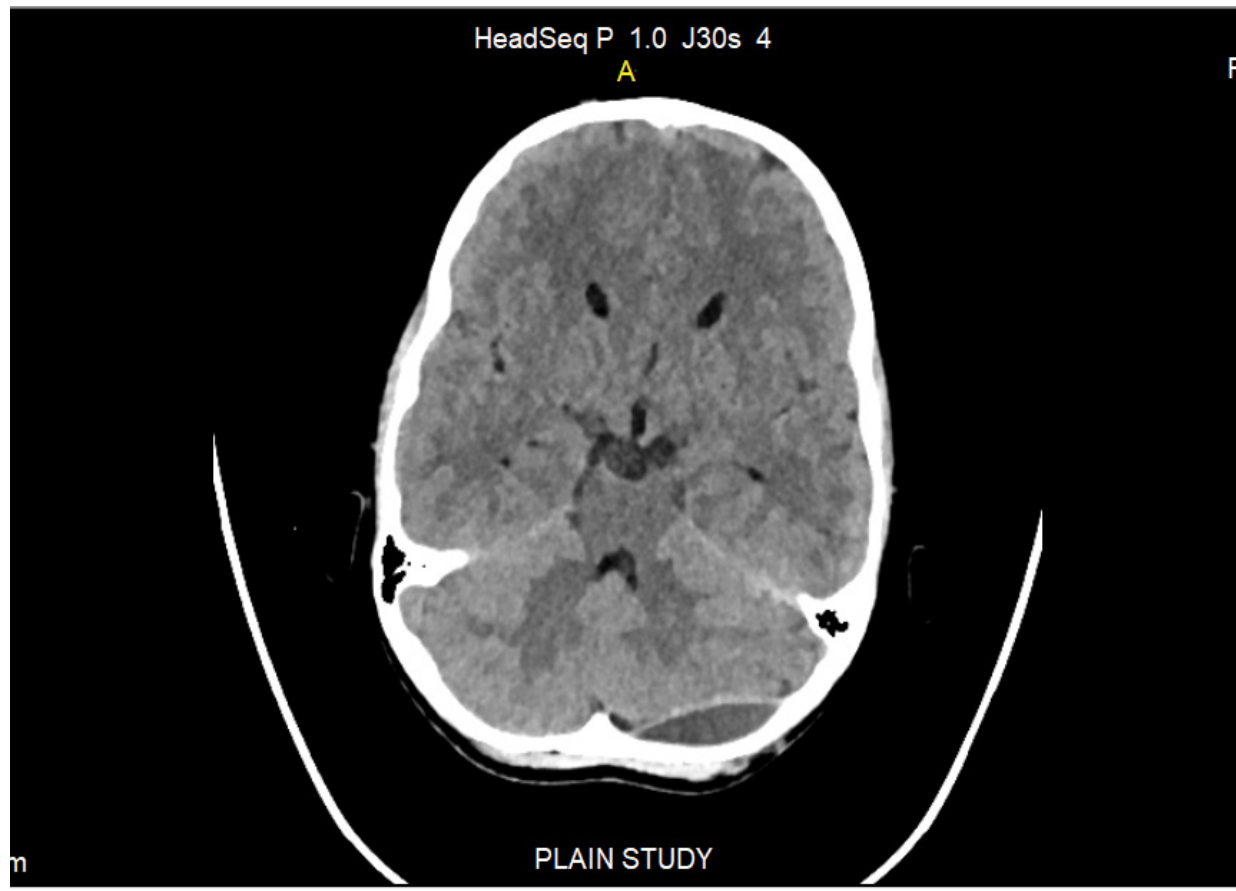

Figure 2: CT scan head (3 weeks after injury), resolving left posterior Foss extra dural haematoma.

of all craniocerebral injuries [5], and $2.7-11 \%$ of all extradural haematomas [6]. All PFEDH which are symptomatic should be operated as early as possible. According to the guidelines for surgical management of traumatic brain injury by 'the brain trauma foundation $\&$ the congress of neurological surgeons,' extra dural haematoma with volume greater than $30 \mathrm{ml}$ should undergo surgical evacuation, regardless of GCS. PFEDH is not described separately in these guidelines. There are no definite guidelines when to operate and when not to operate a PFEDH in neurologically normal patients. According to some authors different criteria for surgical evacuation of PFEDH included are haematoma volume $>10 \mathrm{ml}$, haematoma thickness $>15 \mathrm{~mm}$, perimesencephalic cisterns obliteration, fourth ventricle displacement and hydrocephalus. In this patient PFEDH volume was $20 \mathrm{ml}$, haematoma thickness was $20 \mathrm{~mm}$, perimesencephalic cisterns and fourth ventricle obliterated, which should have been surgically evacuated immediately, according to most of 


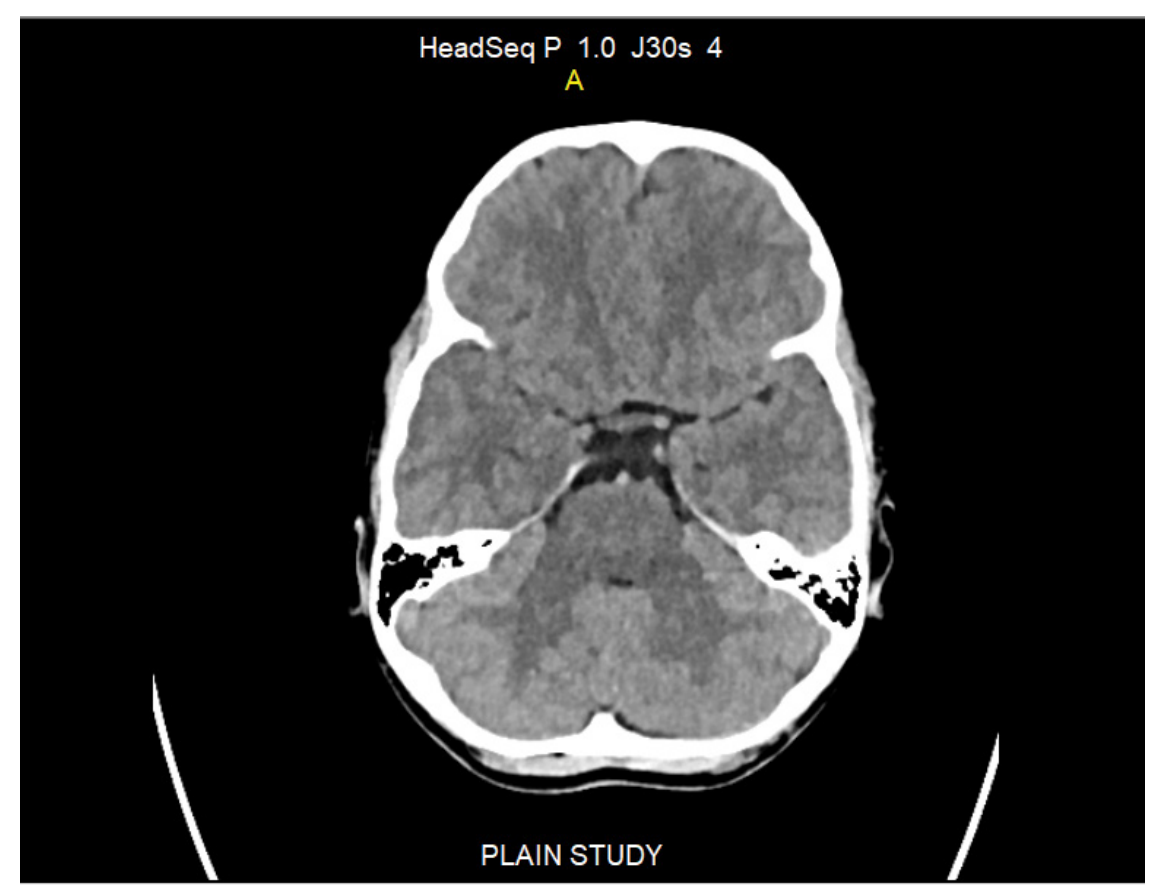

Figure 3: CT scan head (6 weeks after injury) showing complete resolution of left posterior fossa extra dural haematoma.

the authors. Patient's family was reluctant in opting for any surgical intervention, hence, the patient was treated conservatively and was kept under clinical \& radiological assessment regularly. PFEDH resolved completely in six weeks' time, saving patient from unnecessary surgical intervention and risks from anaesthesia \& surgery. This suggests that in patient of asymptomatic PFEDH with significant volume, conservative treatment is a potential approach as shown by other studies. Resolution of extradural haematoma have also reported by Zakaria, et al. $[7,8]$. This case report highlights that neuratrauma surgeons should consider conservative treatment as one of the possible treatments in asymptomatic PFEDH with significant volume.

\section{Conclusion}

Conservative treatment with regular clinical and radiological observations in asymptomatic PFEDH with significant volume (more than $10 \mathrm{cc}$ ) and haematoma thickness more than $15 \mathrm{~mm}$, is a possible treatment option. However, a larger study is needed to further support these findings.

\section{Conflict of Interest}

None.

\section{References}

1. Bullock MR, Chesnut R, Ghajar J, Gordon D, Hartl R, et al. (2006) Surgical management of acute epidural hematomas. Neurosurgery 58: 7-15.

2. Ullman JS, Kopell (2016) Epidural hematomas treatment \& Management. Medscape.

3. Roka YB, Kumar P, Bista P, Sharma GR, Adhikari D (2008) Traumatic posterior fossa extradural haematoma. JNMA J Nepal Med Assoc 47: 174-178.

4. Bor-Seng-Shu E, Aguiar PH, de Almeida Leme RJ, Mandel $\mathrm{M}$, Andrade AF de, et al. (2004) Epidural hematomas of the posterior cranial fossa. Neurosurgical Focus.

5. Garza-Mercado R (1983) Extradural hematoma of the posterior cranial fossa. Report of seven cases with survival. J Neurosurg 59: 664-672.

6. Abe M, Otawara Y, Suzuki M, Tomitsuka N, Ogawa A, et al. (2000) Posterior fossa epidural hematomas: observations on a series of 73 cases. Neurosurg Review 23: 90-93.

7. Zakaria Z, Kaliaperumal C, Kaar G, O'Sullivan M, Marks C (2013) Extradural haematoma - To evacuate or not? Revisiting treatment guidelines. Clin Neurol Neurosurg 115: 1201-1205.

8. Kang SH, Chung YG, Lee HK (2005) Rapid disappearance of acute posterior fossa epidural hematoma. Neurologia Medico-Chirurgica.

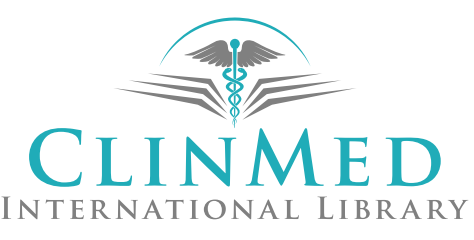

